\section{Andamios Revista de Investigación Social}

(1)
Andamios. Revista de Investigación

Social

ISSN: 1870-0063

revistaandamios@uacm.edu.mx

Universidad Autónoma de la Ciudad de

México

México

Ochman, Marta

Políticas sociales focalizadas y el dilema de la justicia

Andamios. Revista de Investigación Social, vol. 11, núm. 25, mayo-agosto, 2014, pp. 147-169

Universidad Autónoma de la Ciudad de México

Distrito Federal, México

Disponible en: http://www.redalyc.org/articulo.oa?id=62836852007

- Cómo citar el artículo

- Número completo

- Más información del artículo

- Página de la revista en redalyc.org

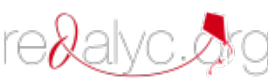

Sistema de Información Científica

Red de Revistas Científicas de América Latina, el Caribe, España y Portugal

Proyecto académico sin fines de lucro, desarrollado bajo la iniciativa de acceso abierto 


\title{
Políticas sociales focalizadas y El Dilema dE LA JUSTICiA
}

\author{
Marta Ochman*
}

\begin{abstract}
ResUmen. El artículo analiza el impacto de las políticas sociales focalizadas en la distribución de los bienes primarios materiales (ingreso y riqueza) y simbólicos (bases sociales de respeto a sí mismo). Recupera los aportes de Esping-Andersen, así como los estudios realizados en Estados Unidos sobre el apoyo a programas focalizados. La tesis es que las políticas focalizadas, aunque impactan positivamente en la distribución justa de bienes materiales, minan las bases sociales de respeto a sí mismo.

Palabras Clave. Focalización, estigmatización, justicia, merecimiento, igualdad simbólica.
\end{abstract}

Ante la persistencia, e incluso el crecimiento, de la pobreza en América latina, el tema de las políticas sociales, su diseño y las fuentes de su financiamiento, siguen ocupando un papel central en la discusión sobre la agenda pública. Desde la década de 1990 — cuando el consenso de Washington determinaba la transformación de los estados latinoamericanos-, el paradigma del diseño de los programas redistributivos fue la focalización, aceptada como condición necesaria de políticas sociales en estados con problemas de pobreza extendida y de déficits fiscales permanentes (Hernández et al., 2005; CEPAL, 2000). Sin embargo, es necesario retomar el debate sobre el impacto de la focalización en la justa distribución de bienes no solamente materiales, sino también simbólicos, y particularmente su relación con la estigmatización de los grupos vulnerables, beneficiados materialmente con las políticas sociales focalizadas.

\footnotetext{
* Profesora de planta en la EgAP, Gobierno y Política Pública, del Tecnológico de Monterrey, sede Estado de México. Miembro del Sistema Nacional de Investigadores, nivel I. Dirección electrónica: mochman@itesm.mx
} 
La tesis que sustento es que las políticas focalizadas, aunque pueden ser defendidas con base en el argumento de la justicia —y no sólo de la eficiencia - presentan un reto importante para sus diseñadores, dado que intrínsecamente conllevan el riesgo de exclusión simbólica, y por ende niegan el acceso a uno de los bienes primarios (Rawls, 2003): las bases sociales del respeto a sí mismo.

Iniciaré con un breve análisis de la relación entre el principio de justicia de Rawls $(1995,2003)$ y su relación con la igualdad simbólica de Fraser (1997), como marco teórico del debate clásico sobre la focalización, centrado en el argumento de la justicia, determinada por el grado de la independencia del individuo del mercado (Esping-Andersen, 1990). Este planteamiento considera que el diseño institucional de las políticas sociales (focalización vs. provisión universal) determina, además, el grado de aceptación de éstas por parte de los electores, por ende, su sustentabilidad fiscal.

En contraposición, en la tradición estadounidense, los estudios empíricos se han centrado en determinar la importancia de factores individuales, recuperando particularmente el concepto de merecimiento (deservingness), como factor que determina la aceptación o el rechazo de las políticas sociales focalizadas. Ambos planteamientos apuntan a la misma conclusión: la focalización de las políticas públicas dificulta una justa distribución de la estima social, fenómeno que a la larga, puede minar un apoyo social a los mecanismos redistributivos.

\section{JUSTICIA E IGUALDAD SIMBÓLICA}

El concepto de justicia política y de los bienes primarios (Rawls, 2003) constituye un referente adecuado para las políticas públicas, tanto por su énfasis en el "igual derecho a exigir un esquema de derechos y libertades básicos e igualitarios", como por el principio de ejercer el poder y los cargos políticos en el máximo beneficio de los integrantes menos privilegiados de la sociedad (2003: 31). Aunque Rawls enfatiza ante todo la distribución igualitaria de las libertades básicas, en su descripción de los bienes primarios, además de aquellas, incluye los ingresos y la riqueza, así como las bases sociales de respeto a sí mismo (2003: 177; 285-286). La 
relevancia del planteamiento de Rawls para las políticas públicas reside en la función de los bienes primarios como marco de referencia de los reclamos de los ciudadanos sobre los recursos del Estado. Siendo una concepción liberal, la teoría de la justicia de Rawls asigna a los individuos la responsabilidad de hacer realidad sus proyectos de vida, y limita la responsabilidad del poder público a asegurar un acceso equitativo a los bienes primarios (Rawls, 2003: 185).

El principio de justicia de Rawls y el concepto de bienes primarios constituyen así un encuadre teórico muy apropiado para discutir la legitimidad de las políticas sociales focalizadas. En primera instancia, el permitir la desigualdad siempre y cuando se ejerza en favor de los más vulnerables, así como la inclusión de ingresos y riqueza en los bienes primarios, es un argumento muy poderoso en favor de la focalización, desde el enfoque pragmático de la eficiencia, que retomaré más adelante. Sin embargo, la focalización hace evidente la tensión entre el acceso a los bienes materiales y a las bases sociales de respeto a sí mismo, fenómeno que se ha estudiado mucho en el contexto de las políticas sociales en términos de la igualdad material y la simbólica.

Generalmente, se considera que existe una relación intrínseca entre la igualdad material y la simbólica (CEPAL, 2000; Fraser, 1997), dado que la desigualdad material promueve el aislamiento de los grupos privilegiados y su refugio en el espacio privado, por ende la guetificación y la criminalización de los pobres (Bauman, 2002: 142-148). En el planteamiento de la CEPAL:

Las élites tienden cada vez más a autoexcluirse de la vida ciudadana y refugiarse en territorios amurallados. No interactúan con otros grupos en la ciudad salvo en calidad de empleadores o directivos de empresas. Generan y pagan sus propios sistemas educativos y dan clara prioridad a sus vínculos con pares de otros países frente a la opción de vincularse con la propia sociedad (CEPAL, 2000: 308).

La desigualdad material fomenta entonces la simbólica, que se manifiesta en los patrones sociales de representación del Otro: 
Los ejemplos de este tipo de injusticia incluyen la dominación cultural (estar sujeto a patrones de interpretación y comunicación asociados con otra cultura y ser extraños $u$ hostiles a los propios); el no reconocimiento (hacerse invisible a través de prácticas representativas, interpretativas y comunicativas de la propia cultura); y el irrespeto (ser calumniado o menospreciado habitualmente en las representaciones culturales públicas estereotipadas o en las interacciones cotidianas) (Fraser, 1997: 5).

Esta relación bidireccional entre los dos tipos de desigualdad, en el caso de las políticas focalizadas, se constituye en un círculo vicioso: a menor igualdad simbólica, menor apoyo a políticas sociales orientadas a reconstruir la igualdad material. Como se verá en el análisis del debate sobre la focalización, esta relación circular entre la desigualdad material y la simbólica es fundamental para entender los conceptos de estigmatización y de merecimiento. La estigmatización de los pobres como irresponsables, viciosos o delincuentes conlleva lógicamente la percepción de que éstos no merecen la ayuda pública, por ser moralmente inferiores o por ser responsables de su propio destino.

\section{El DEBATE CLÁSICO SOBRE LA FOCALIZACIÓN}

En este debate, ${ }^{1}$ es posible sistematizar los argumentos en dos categorías: los pragmáticos, orientados al criterio de la eficiencia; y los axiológicos, centrados en el principio de justicia. ${ }^{2}$ El principal argumento pragmático

\footnotetext{
Véase Hernández et al., 2005; Sefton, 2006; Gordon, 2003; Gordon, 2001, Larsen, 2008 o Huber, 1996.

${ }^{2}$ Los argumentos aquí presentados no reflejan todo el debate, que se nutre no solamente de las diferencias fundamentales entre programas focalizados y de cobertura universal, sino también del análisis de programas específicos, que tienen impacto indeseable, fomentando por ejemplo el caciquismo o desincentivando la participación laboral de la mujer. Sin embargo, son fallas posibles de corregir modificando el diseño de cada programa, de ahí que no los considero significativos para el debate sobre la justicia.
} 
en favor de la focalización reitera que ésta asegura el uso más eficiente de los recursos disponibles - y escasos - y en este sentido las políticas sociales focalizadas son más efectivas, sobre todo en países con mayores niveles de desigualdad. Este hecho conlleva lógicamente la disminución de los costos fiscales, y por ende menor rechazo a las políticas sociales del Estado, haciéndolas sustentables a largo plazo.

Los detractores de la focalización rebaten este planteamiento, afirmando que los costos administrativos de la focalización — determinar quién tiene la necesidad - neutralizan la eficiencia fiscal. Adicionalmente, consideran que la focalización no permite atender a todos los necesitados, por dos razones: la necesidad es frecuentemente difícil de demostrar, al mismo tiempo que demostrarla implica costos para los pobres, vinculados con trámites, desplazamiento, etcétera. De ahí que, según Sefton (2006) existe evidencia empírica de que los programas focalizados son menos efectivos en la disminución de la pobreza que los sistemas universalistas. En cuanto a la sustentabilidad, consideran que la permanencia de los programas sociales no depende únicamente de la percepción sobre su costo fiscal, sino también del apoyo político: siendo los pobres políticamente débiles y sub-representados, este apoyo iría disminuyendo independientemente de la eficiencia fiscal. ${ }^{3}$ En la lógica axiológica, los partidarios de la focalización afirman que ésta corresponde al principio de justicia, dado que

[...] ante los recursos necesariamente escasos para atender a todos o a todas las necesidades, tan importante es asegurar que se beneficien quienes más lo necesitan, como no destinar recursos a quienes no se encuentran en una situación apremiante. La focalización es una forma de promover la equidad, por lo que su ausencia puede, incluso, ampliar las brechas de injusticia y aumentar la inequidad (Hernández et al., 2005: 5).

En este planteamiento, el problema principal de los sistemas universalistas es el fenómeno de la "captura por la clase media" (Sefton, 2006): dado

\footnotetext{
${ }^{3}$ Véase, por ejemplo, el debate sobre la underclass en Dahrendorf (1995), o Gans (1992).
} 
que los pobres enfrentan las barreras culturales — conocen menos sus derechos-y transaccionales - trámites y desplazamiento-, es la clase media quien se beneficia más de los programas sociales universales. Para evitarlo, frecuentemente, el gobierno baja el nivel de los servicios ofrecidos, para desincentivar su uso por individuos con capacidad de pagar los mismos servicios privados.

Para los defensores de los programas de cobertura universal, uno de los problemas de la focalización es la intrusión del Estado en la vida personal de los individuos y en sus finanzas, inherente al procedimiento administrativo de identificar a los posibles beneficiarios; pero el grueso del debate se centra en el fenómeno de estigmatización. En palabras de Nancy Fraser, la focalización

[aunque] busca remediar la injusticia económica, deja intactas las estructuras profundas que generan las desventajas de clase. Por lo tanto, debe hacer reasignaciones superficiales una y otra vez. El resultado es que la clase menos favorecida queda marcada como inherentemente deficiente e insaciable, como si siempre necesitara más y más. Con el tiempo, puede parecer incluso que se privilegia a dicha clase, por cuanto es objeto de un trato especial y de una generosidad inmerecidos. Por consiguiente, una aproximación dirigida a resolver las injusticias de redistribución puede terminar generando injusticias de reconocimiento (1997: 22).

La estigmatización es el efecto de que los programas sociales focalizados se perciben como caridad, como ámbito de acción filantrópica, y no como ejercicio de los derechos universales o ciudadanos, percepción fomentada por el sistema de servicios públicos universales. Adicionalmente, la estigmatización es el resultado de los controles que establecen los programas focalizados para protegerse de los posibles fraudes, creando la percepción de que el grupo beneficiado —además de económicamente ineficiente- es deshonesto. Los defensores de la focalización reconocen este riesgo, pero no lo consideran exclusivo de la focalización. La captura de los servicios universales por la clase media, y la estrategia de bajar el nivel de servicios para promover el uso de 
servicios privados, lleva finalmente a la estigmatización de los usuarios de los servicios públicos, en el mismo grado que la focalización.

La distinción entre argumentos pragmáticos y axiológicos es una distinción analítica; en realidad, ambos enfoques se entrecruzan en la preocupación por el apoyo social y político a los programas sociales: la estigmatización disminuye la cohesión social y fragmenta la estima social igualitaria para todos los ciudadanos, creando grupos con percepciones antagónicas sobre sus propios intereses, y por ende, con preferencias distintas en cuanto a la política pública. La estigmatización no es, entonces, solamente una forma de discriminación, es también un obstáculo para crear una sociedad capaz de construir consensos en torno a la agenda pública y sus prioridades.

El fenómeno de estigmatización es central para las políticas sociales porque el ámbito de las políticas redistributivas es considerado también como el más conflictivo (Lowi, 2000). Uno de los factores que provoca el rechazo a los programas focalizados, es la percepción de que los beneficios se redistribuyen desde los ricos y la clase media hacia los pobres, o que favorecen de manera desproporcionada a ciertos sectores (niños, jóvenes o adultos mayores), mientras que la población económicamente activa debe asumir el grueso del costo de los servicios (educación, salud y pensiones). Esta percepción fomentaría, lógicamente, el rechazo a las políticas redistributivas, o en dado caso las presiones para reducir el gasto público destinado a financiarlas, minando así su sustentabilidad fiscal. En contraste con la focalización, los programas de cobertura universal provocan menor rechazo, dado que la relación entre el costo y el beneficio se nivela en el transcurso de la vida de la persona (Sefton, 2006).

El interés por la relación entre la focalización y la estigmatización está en gran medida determinado por la clásica obra del sociólogo danés, Gøsta Esping-Andersen (1990), ${ }^{4}$ y su tipología del Estado benefactor. Un criterio importante de la distinción entre el Estado benefactor liberal, el corporativo y el socialdemócrata, es el grado de desmercantilización del trabajo; es decir, la capacidad de los individuos de vivir en condiciones

\footnotetext{
${ }^{4}$ Este resumen de Esping-Andersen retoma también los planteamientos de Christian Larsen (2008) y Tom Sefton (2006).
} 
aceptables, independientemente de su participación en el mercado, misma que depende de la amplitud de los derechos sociales y su universalidad. El Estado benefactor liberal — cuyo ejemplo paradigmático es Estados Unidos- responde al presupuesto de que el mercado debe ser el proveedor principal del bienestar, mientras que el gobierno sólo debe corregir las fallas del mercado: el argumento clásico en favor del Estado mínimo. El Estado interviene en casos extremos cuando las familias no son capaces de proveerse del bienestar mínimo, de ahí que la focalización es el mecanismo preferencial, en el cual —adicionalmentelas reglas sobre quién es el beneficiario son muy estrictas, los niveles de los beneficios modestos y el tiempo de provisión limitado, para no desincentivar la filantropía o el esfuerzo personal por proveerse de bienes. Una de las preocupaciones del Estado benefactor liberal es la cultura de la dependencia, que percibe a los pobres como individuos sin aspiraciones de progresar.

El Estado corporativo — cuyos ejemplos son Francia o Alemaniaconcibe la redistribución como ayuda mutua para los que enfrentan circunstancias difíciles. Los beneficios son generosos, pero dependen de las contribuciones acumuladas por medio del trabajo asalariado. Dado que es un sistema basado en contribuciones, no exige que se demuestre la necesidad; pero los derechos sociales no son concebidos como derechos ciudadanos, sino laborales. El papel del Estado corporativo consiste básicamente en facilitar esquemas de aseguramiento, y también proveer servicios a los que no son normalmente parte del mercado laboral, según el esquema del Estado liberal (servicios mínimos y focalizados).

Finalmente, el Estado benefactor socialdemócrata —ejemplificado por los países escandinavos- asume que el mercado y la distribución de bienes en los regímenes capitalistas son injustos, de ahí que considera legítima la intervención en las reglas del mercado para asegurar los fines sociales de la economía. La redistribución implica la desmercantilización de ciertos bienes y servicios (salud, educación, alojamiento) y su distribución más equitativa que el ingreso o la riqueza. Los derechos a estos bienes y servicios son parte de los derechos ciudadanos, y se proveen a través de sistemas de aseguramiento universal, de manera que los utilizan incluso personas con ingresos altos. El nivel de provisión tiene como referencia el nivel de vida de personas con ingreso medio. 
Como se puede apreciar, en la tipología de Esping-Andersen, el diseño de las políticas sociales tanto en el Estado liberal, como en el corporativo, más que asegurar la independencia del individuo busca crear incentivos para el mercado. Las ayudas mínimas a los pobres estimulan su incorporación a los mecanismos del consumo y del empleo; los sistemas de aseguramiento a través del trabajo asalariado incentivan la incorporación de los individuos al mercado laboral. Solamente el Estado socialdemócrata asegura la desmercantilización de las prestaciones sociales y su transformación en derechos ciudadanos universales.

Como cualquier modelo teórico, el esquema de Esping-Andersen difícilmente puede observarse en la realidad actual de las políticas sociales, ${ }^{5}$ las cuales incorporan, de hecho, sistemas mixtos de derechos universales, esquemas de aseguramiento y ayudas focalizadas. La importancia de este planteamiento radica en poner en el centro del análisis el impacto del diseño institucional de las políticas sociales sobre el acceso al bien primario de la estima social como fundamento del respeto a sí mismo. En el caso extremo, las políticas sociales mínimas estigmatizan a los receptores de ayuda como los miembros deficientes, ineptos, incapaces de cumplir con la obligación fundamental del individuo de responsabilizarse por su propio destino. Pero las prestaciones vinculadas con el trabajo asalariado también crean una sociedad estratificada, primero entre los que tienen el empleo y los desempleados; y en segundo término, entre los miembros de sindicados fuertes, con contratos colectivos generosos, y los contratados en sistemas flexibles, con sueldos y prestaciones mínimas. Actualmente, con el desempleo estructural generalizado, muchos jóvenes no se incorporan al mercado laboral, por ende, no acumulan derechos a la protección social, y caen en los sistemas de ayuda adicionales, propios del Estado liberal. Solamente

\footnotetext{
${ }^{5}$ El modelo de Esping-Andersen fue creado para analizar el Estado benefactor de países occidentales, Europa y Estados Unidos. Para el caso de Latinoamérica, Filgueira y Filgueira (2002) proponen una distinción entre el universalismo estratificado (Argentina o Chile), regímenes duales (México o Brasil) y regímenes excluyentes (Guatemala o Bolivia). El caso de los regímenes excluyentes es particularmente interesante porque implica que los servicios públicos estaban beneficiando exclusivamente a los sectores con mayor poder económico y político, mientras que la mayoría de la sociedad estaba excluida de la protección del Estado.
} 
el modelo socialdemócrata desvincula la política social de la categoría de clase o grupo, y lo plantea como un derecho ciudadano. En los sistemas de beneficios y servicios universales no existe la necesidad de establecer quién tiene la necesidad y quién no; lo cual hace irrelevante también la discusión sobre el grado en que los individuos son responsables por estar necesitados. El debate más bien se centra en la cuestión de cómo se define la justicia en las relaciones entre los ciudadanos y el Estado. La pregunta no es cómo resolver el problema de los pobres, sino cómo resolver el problema general de la educación o la salud (Larsen, 2008). El nivel generoso de los servicios resuelve también el problema de la captura de servicios por la clase media, descrito anteriormente, y permite una convivencia entre los diferentes estratos socioeconómicos en el sistema educativo, de salud, e incluso en los mismos espacios geográficos de las ciudades, promoviendo así la distribución igualitaria de la estima social y la percepción de que el efecto redistributivo de las políticas sociales se iguala a través del ciclo de vida de los individuos.

En conclusión, el planteamiento de Esping-Andersen, y el debate tradicional sobre la focalización en las políticas sociales enfatizan la importancia del diseño institucional de las políticas públicas. La focalización o la provisión universal de los bienes y servicios fomentan una percepción distinta sobre las políticas sociales y sus beneficiarios. Sin embargo, si aceptamos que el diseño institucional impacta los valores y las actitudes de la sociedad, es legítimo considerar que esta relación es bidireccional: los valores predominantes en una sociedad tienen impacto en el diseño de las políticas.

\section{CONDICIONAMIENTOS INDIVIDUALES DE LAS POLÍTICAS SOCIALES}

Si el planteamiento de Esping-Andersen no se basa en la distinción generalmente aceptada entre los sistemas de valores anglosajones y los de Europa continental (Ochman, 2008; Gilens, 1999), indudablemente ha reforzado la percepción de que el diseño de la política pública, y de las políticas sociales particularmente, depende de las creencias, las ideologías y los valores predominantes en una sociedad dada. Finalmente, su clasificación del Estado benefactor es ilustrada con 
países que corresponden también a la distinción entre las sociedades anglosajonas — preocupadas por la libertad individual_y las europeas, más apegadas al principio de la justicia social.

La validez empírica de este planteamiento ha sido poco estudiada en Latinoamérica; en cambio, tiene una tradición ya cimentada en Estados Unidos (Bobo 1993; Bobo y Kluegel, 1998; Hetling et al., 2008; Sefton, 2006; Blinder, 2007; Gainous, 2008; Larsen, 2008; Gilens, 1999). ${ }^{6}$ Para fines de los estudios empíricos, los autores identifican diferentes variables que, teóricamente, determinarían la percepción sobre las políticas sociales. Hetling et al. (2008), por ejemplo, miden ocho variables: interés, creencias y valores, experiencia, ideología, predisposición política, creencias sobre el merecimiento, estereotipos raciales y factores demográficos (raza, sexo, edad, etcétera). Blinder (2007) las reduce a tres: demográficos, ideológicos y actitudinales; mientras que Bobo (1993) o Gilens (1999) consideran el interés propio, el sistema de valores y el racismo. Consideraré aquí la distinción en tres factores, cercana a la de Bobo y Gilens, aunque sustituyo el criterio de raza por el concepto más amplio del merecimiento (deservingness), que de manera más o menos explícita aparece en todos los estudios, frecuentemente como parte de la ideología o del sistema de valores. Voy a defender aquí que el merecimiento es una percepción, un juicio de valor, influido tanto por el componente cognitivo, como el axiológico. La lógica de considerar el merecimiento como un factor independiente del cognitivo y del axiológico, es no solamente su estructura mixta, sino también los resultados de los estudios empíricos: existe el consenso en que el sistema de valores, las ideologías, las características demográficas o el interés propio tienen un impacto limitado sobre la actitud ante las políticas sociales o de acción afirmativa; mientras que la percepción sobre el merecimiento juega el papel fundamental. Antes de profundizar en el concepto de merecimiento, describiré brevemente el factor del interés propio y del sistema de valores, para entender el porqué de su impacto limitado.

\footnotetext{
${ }^{6}$ Los estudios estadounidenses no solamente toman como objeto de estudio a las políticas sociales, sino también las de acción afirmativa (discriminación positiva); es decir, estudian los factores que determinan el apoyo a las políticas redistributivas en general.
} 
El argumento del interés propio afirma que los individuos apoyarán las políticas públicas que los favorecen directamente, en cambio, rechazarán políticas cuyos costos deben asumir, mientras los beneficios no están determinados o recaen en otros grupos. El presupuesto teórico es que los individuos son egoístas y racionales, evalúan las políticas públicas con base en el conocimiento de la relación entre el costo y el beneficio, y una clara percepción de su propio interés (o el interés de su familia). En el ámbito de las políticas sociales, lógicamente, las clases media y alta serían antagónicas a las políticas sociales focalizadas en los pobres, mientras que los pobres, las apoyarían. Otra forma de comprobar la relevancia del interés propio es medir las variaciones en el apoyo a las políticas públicas en los tiempos de auge y de crisis económicas: en las épocas de crisis, el apoyo debería disminuir, dado que disminuye también la cantidad de dinero destinada a la satisfacción de las necesidades básicas individuales o de la familia.

El estudio de Gilens (1999) resume de manera más completa los resultados empíricos, mismos que niegan la importancia del interés egoísta. Por un lado, en las épocas de crisis, el apoyo a las políticas sociales crece, dado que la falta del éxito individual se atribuye a las circunstancias del contexto, y no al escaso esfuerzo personal (Gilens, 1999: 45-52). Por otro lado, aunque es cierto que las clases alta y media manifiestan menor apoyo a las políticas sociales focalizadas y prefieren las de cobertura universal — que los incluyen en los beneficios-, Gilens considera que la explicación no está en la percepción sobre el interés, sino sobre el merecimiento y la experiencia distinta. La hipótesis de que un factor significativo es la experiencia diferente, es apoyada por ejemplo, por la encuesta de Los Angeles Times sobre las percepciones de la pobreza y el Estado benefactor, aplicada en 1985. Resumiendo los resultados, Gilens (1999: 54-57) demuestra que son similares los porcentajes de los pobres y los no pobres que están de acuerdo en que las personas que viven la pobreza son trabajadoras; en cambio, mientras el $60 \%$ de los no pobres considera que siempre hay trabajo disponible para los que quieren trabajar, el porcentaje baja a 34\% en el caso de los pobres. De igual manera, el $77 \%$ de los no pobres y sólo el $58 \%$ de los pobres, consideran que la mejor solución al desempleo es la capacitación (Gilens, 1999: 56). 
Por su parte, el rechazo a las políticas focalizadas no está determinado por la focalización misma —es decir, por el beneficio limitado a unos pocos-, sino por las características del grupo beneficiado o el carácter del servicio ofrecido. En este sentido, por ejemplo, existe un amplio apoyo para los programas focalizados en los veteranos; también, mientras es escaso el apoyo a la transferencia directa de dinero, la tendencia se revierte en programas focalizados de asistencia médica (Gilens, 1999: 42-45). Finalmente, la importancia relativa del interés propio queda demostrada cuando se pide a los encuestados de clase media escoger entre las afirmaciones de que el gobierno debe apoyar a los pobres o a la clase media: la mayoría considera que el apoyo a los pobres es más importante que a la clase media (Gilens, 1999: 43).

El argumento del sistema de valores considera básicamente que la diferencia en el apoyo a las políticas sociales se explica por el valor del individualismo, predominante en las sociedades anglosajonas; frente a los valores de la justicia y la igualdad, predominantes en las sociedades europeas. El individualismo da preferencia a la responsabilidad y la libertad individual, de ahí que plantea la exigencia del Estado mínimo, que no aumente la dependencia individual del gobierno. Las políticas sociales universales se nutren de una interpretación muy distinta de la responsabilidad individual: consideran que las desigualdades son provocadas por las injusticias históricas, de ahí que la intervención del Estado para restablecer la equidad corresponde al principio de la justicia correctiva (Kershnar, 1999). En síntesis, los estadounidenses asignan la responsabilidad por la pobreza al individuo, mientras que los europeos al sistema social y económico (Gilens, 1999; Sefton, 2006).

Los estudios empíricos demuestran la persistencia del sistema de valores individualista en la sociedad estadounidense; por ejemplo, según los datos citados por Gilens, el 96\% considera que las personas deben aprovechar cada oportunidad que se les presenta para mejorar su situación, en vez de esperar la ayuda del gobierno; y el 80\% considera que para ser un verdadero estadounidense, es extremadamente y muy importante progresar por esfuerzo propio. Sin embargo, al mismo tiempo entre el 80 y el $90 \%$ de los encuestados apoya la ayuda gubernamental a los pobres y cree que el gobierno debería estar involucrado en el combate a la pobreza (Gilens, 1999: 35). De ahí que la relación entre 
el individualismo y las políticas sociales es más compleja: determina más bien las preferencias en el diseño de las políticas sociales, que el rechazo al concepto mismo. Por ejemplo, el apoyo es menor a la transferencia directa del dinero, que a los programas de fomento al empleo, la capacitación o la salud.

Las conclusiones de Gilens en el sentido de que el factor más importante en la percepción de las políticas sociales es el merecimiento, coinciden con otros autores aquí citados. Las encuestas señalan que la abrumadora mayoría de los estadounidenses percibe que los beneficiados por los programas, en gran medida, no necesitan esta ayuda, abusan de los programas, son flojos, borrachos, etcétera. El 74\% considera que los criterios de inclusión en programas no son suficientemente duros y que se debe "investigar" mejor a los beneficiados (Gilens, 1999: 61-67). Incluso los estudios de Bobo (1998) y Bobo y Kluegel (1993) sobre el racismo y las políticas focalizadas con el criterio de raza (acción afirmativa) concluyen que los estereotipos raciales todavía vigentes estigmatizan a los afroamericanos como flojos, y por ende, no merecedores de la ayuda pública.

\section{EL MERECIMIENTO Y LAS POLÍTICAS SOCIALES}

¿En qué consiste entonces el criterio de merecimiento? Ante todo, hay que considerar que la percepción de que gran parte de los beneficiados por la ayuda pública no la merece, no es un fenómeno reciente. Linda Gordon (2001) plantea que está inherente en el carácter moral de las comunidades humanas. Incluso antes del surgimiento de las políticas públicas, las comunidades consideraban un deber moral encargarse de los miembros incapaces de satisfacer sus necesidades. Este deber crea una tensión entre la evaluación positiva o la satisfacción personal que implica ayudar, y el rechazo a los que aprovechan esta ayuda sin merecerla. De ahí que el criterio de la necesidad siempre fue acompañado por el requisito de una buena reputación moral, que equivalía a la percepción de que los individuos necesitados eran al mismo tiempo miembros (moralmente) valiosos de la comunidad. En las comunidades premodernas, la conducta y la reputación eran fácilmente observables, 
pero en los estados modernos la convivencia cotidiana ha sido sustituida por los mecanismos impersonales y los controles burocráticos. La despersonalización de las relaciones entre los miembros de una comunidad — los ciudadanos en los estados modernos- crea mayor desconfianza en los sistemas sociales, y la percepción de que, incluso si existe la necesidad, ésta es el efecto de la conducta irresponsable - $\mathrm{y}$ moralmente cuestionable- de los beneficiarios: el abuso del alcohol o de las sustancias tóxicas, los embarazos irresponsables, la pereza, etcétera.

La percepción sobre quién merece y quién no, la ayuda pública tiene una estructura compleja, que se puede analizar a través de cinco elementos constitutivos (Larsen, 2008):

1. El control sobre las causas de la necesidad: mientras menos controla el sujeto las causas de su vulnerabilidad, mayor percepción de que merece la ayuda pública. Un ejemplo es el aumento de apoyo a los programas sociales en épocas de crisis, citado por Gilens (1999), cuando los orígenes del desempleo o del ingreso insuficiente se atribuyen al contexto y a los factores estructurales y no a la falta del esfuerzo personal. Otro ejemplo muy común es el apoyo solidario a las comunidades afectadas por los desastres naturales, o los altos grados del consenso sobre la responsabilidad del Estado por el derecho a la salud.

2. Necesidad: a mayor grado de necesidad, mayor percepción del merecimiento; de ahí que existe un consenso sobre la necesidad de atender a la población en pobreza extrema.

3. Identidad: mientras mayor grado de pertenencia a un grupo, mayor grado de merecimiento. En el sentido más amplio, es la pertenencia a una comunidad nacional, pero actualmente la identidad nacional está viviendo un proceso de erosión frente a las identidades locales. De ahí la presión de los gobiernos locales para disminuir la transferencia de los recursos fiscales al gobierno central, y destinarlos a satisfacer las necesidades locales. El criterio de raza sigue siendo un determinante fuerte de una identidad compartida, y gran parte de los estereotipos negativos son todavía legado de la discriminación racial del pasado o del rechazo a los patrones culturales desconocidos y marginados.

4. Actitud: mientras más dócil es el grupo, más agradecido el individuo, mayor grado de merecimiento. Este criterio demuestra que la 
ayuda pública no se percibe como un derecho inherente - a diferencia de los derechos civiles, por ejemplo- sino que refleja el pensamiento comunitarista resumido por Linda Gordon (2001): la aportación mínima del individuo receptor de la ayuda debe ser su contribución a la armonía colectiva.

5. Reciprocidad: mientras mayor fue la contribución pasada o más probable es la retribución futura, mayor grado de merecimiento. Este criterio explica alto grado de consenso en la necesidad de apoyo a los niños y jóvenes, quienes apenas se están integrando a la sociedad económicamente activa; o a las personas mayores, quienes se consideran merecedoras del apoyo público por los años del trabajo en el pasado. También se pueden recordar los resultados de los estudios de Gilens (1999), que demuestran un constante apoyo de los estadounidenses a los programas destinados a los veteranos.

Como he señalado, muchos investigadores consideran que la percepción sobre el merecimiento es fomentada por la estructura focalizada de las políticas sociales, mientras que los sistemas universales de servicios la debilitan (Gordon, 2001; Larsen, 2008; Huber, 1996). Es evidente, por ejemplo, que la focalización establece criterios definidos y burocráticos para evaluar el grado de necesidad y determinar si ésta justifica el derecho a la ayuda pública.

Estos criterios, además, crean nuevas fronteras identitarias entre los receptores de la ayuda y la mayoría capaz de proveerse con sus propios recursos. Los sistemas universales, en contraste, al definir las políticas sociales como el ámbito de los derechos ciudadanos, fortalecen la identidad nacional, e incluso ayudan a borrar las diferencias de clase, dado que todos los ciudadanos usan los mismos servicios, independientemente de sus ingresos o la riqueza acumulada. De igual manera, el concepto de los derechos sociales cierra los espacios para debatir si los receptores son suficientemente agradecidos y dóciles, o incluso, si tienen necesidad de servicios financiados con recursos públicos.

Sin embargo, incluso si los planteamientos de Larsen (2008), son ilustrados con estudios empíricos, sigue siendo válida la pregunta sobre la dirección de la causalidad entre el diseño de las políticas públicas y la percepción sobre el merecimiento. ¿Las sociedades escandinavas no 
evalúan las políticas sociales con el criterio de merecimiento porque viven en los sistemas universales de provisión de servicios? O más bien han implementado en algún momento de su historia estos sistemas porque tenían una fuerte identidad nacional y un sistema de valores orientado más a la justicia social que al éxito individual. Si recordamos, por ejemplo, la propuesta clásica de Marshall (1992) de la ciudadanía como un disfrute de los derechos civiles, políticos y sociales, la definición claramente está basada en el concepto del merecimiento: ${ }^{7}$ la ciudadanía está vinculada con la pertenencia a una comunidad nacional (identidad compartida), y por ende a compartir la herencia social acumulada (reciprocidad), a cambio de la lealtad a los valores y las leyes de esta sociedad (reciprocidad y actitud). El arraigo que tiene esta conceptualización de los derechos ciudadanos — como derechos de grupo, no derechos humanos universales - crea la polarización en torno a los derechos de los inmigrantes a compartir el sistema universal del Estado social. Dado que los inmigrantes no comparten la identidad nacional, tampoco son considerados como los que han contribuido a la construcción del bienestar acumulado, y se perciben como no merecedores de la provisión de bienes y servicios que les corresponden a los connacionales. Aunque es un debate presente en Europa desde la década de 1960, hasta ahora el diseño estructural de las políticas sociales no ha sido capaz de modificar esta percepción. ${ }^{8}$

De ahí que hay que considerar también otros enfoques que permiten explicar cómo se construye y difunde el criterio de merecimiento.

\footnotetext{
7 "La ciudadanía exige una relación de tipo distinto, un sentido de pertenencia a una comunidad, basado en lealtad a la civilización, que constituye una propiedad en común. Es la lealtad de hombres libres, investidos con derechos y protegidos por una ley común" (T. H. Marshall, 1992: 25, traducción propia).

${ }^{8}$ Como ilustración de este fenómeno, se puede mencionar el informe sobre el llamado "turismo de prestaciones", que la Comisión Europea presentó a mediados de 2013, para frenar una ola de medidas restrictivas a la libre movilidad de personas en la Unión Europea, aprobadas por los gobiernos de países como el Reino Unido, Alemania, Holanda o Austria. El informe, basado en datos oficiales de los gobiernos nacionales, demuestra que los inmigrantes europeos registran una tasa de empleo superior a la de los nacionales o que representan menos del $1 \%$ de aquellos que reciben ayudas públicas. Sin embargo, es evidente el crecimiento de los sentimientos antiinmigrantes en Europa, que se traduce también en el fortalecimiento electoral de la extrema derecha.
} 
Gilens (1999) y Hetling et al. (2008), por ejemplo, se centran en el análisis de los medios y la opinión pública, incluyendo el discurso de los políticos. En el análisis de la percepción de las políticas sociales en Estados Unidos, Gilens habla del fenómeno de racialización de la pobreza, que tuvo lugar entre los años 1965 y 1967 y fue efecto de la imagen que los medios masivos crearon sobre los programas sociales: el sesgo en los reportajes, entrevistas e incluso fotografías han creado la percepción en dos sentidos: los afroamericanos son los principales receptores de la ayuda pública y la mayoría de los receptores son borrachos, drogadictos, irresponsables, sin ambición de independencia económica (Gilens, 1999: 133-153). Hetling et al. (2008) centran, en cambio, su atención en el discurso de los políticos. Mientras la élite política y administrativa comulgaba con los ideales de la Nueva Derecha, predominaba en la sociedad estadounidense la percepción de que los programas sociales son costosos, crean la dependencia de los individuos, promueven su irresponsabilidad y desincentivan los esfuerzos de encontrar el trabajo y abandonar los programas sociales. La llegada del equipo de Clinton y su campaña en torno a la reforma del sistema social en 1996 modificó las percepciones sociales y aumentó considerablemente el apoyo a las políticas sociales.

Evidentemente, las posturas que enfatizan la importancia del diseño estructural y las que analizan los discursos predominantes en los medios, no son excluyentes, y lo que comparten es la afirmación de que la percepción sobre el merecimiento es socialmente construida, y por ende, también modificable. ${ }^{9}$ De ahí la necesidad de estudiar la

\footnotetext{
${ }^{9}$ Un planteamiento totalmente distinto es el de Herbert J. Gans (1992) quien considera que la estigmatización de los pobres como los que no merecen la ayuda pública tiene explicación estructural, inherente a una sociedad polarizada. Las funciones sociales de la estigmatización de los pobres, en el planteamiento de Gans, no son intencionales, ni siquiera conscientes; sin embargo, incluso si fueran reconocidas, no serían abolidas, por su función positiva en la sociedad. El autor identifica trece funciones sociales de la estigmatización, y las agrupa en cinco grandes categorías. Las funciones microsociales operan a nivel individual y básicamente permiten a los individuos no estigmatizados considerar a los pobres como responsables de su destino y por ende, merecedores del castigo. Esto a su vez, permite legitimar el distanciamiento físico, minimizando el riesgo de un daño físico. Las funciones económicas se centran sobre todo en el ámbito laboral: dado que los pobres son moralmente inferiores, no merecen la oportunidad de trabajo (disminuyen la presión sobre
} 
percepción sobre el merecimiento en cada uno de sus cinco elementos constitutivos, así como de mapear su relación tanto con el diseño estructural de las políticas sociales, como con el discurso mediático en torno a éstas.

El problema del encuadramiento para construir la percepción de merecimiento de los beneficiarios de los programas sociales focalizados es complejo. Por un lado, es relativamente simple enfatizar los mensajes que transmiten la urgencia de la necesidad o el deber de reciprocidad, sea para agradecer la contribución de los beneficiados a la construcción de una sociedad armoniosa y solidaria (de las madres solas, por ejemplo), sea para reparar injusticias pasadas (en el caso de los pueblos originarios) y restablecer condiciones de equidad (de género, por ejemplo). Sin embargo, particularmente dos elementos del merecimiento - muy utilizados para conseguir el apoyo a las ayudas públicas- conllevan el riesgo de estigmatización de los beneficiados como sujetos de compasión y beneficencia, y no como ciudadanos con derecho a la justa distribución de los bienes primarios. El primer factor está relacionado con el control sobre las causas de la necesidad: frecuentemente los mensajes mediáticos y los políticos victimizan a los beneficiarios, los presentan como individuos débiles, necesitados de ayuda por parte de los miembros exitosos de la sociedad. Esta victimización es reforzada por los mensajes que apuntan a la actitud dócil, de agradecimiento por la protección, por ser rescatados de las dificultades que padecen. ${ }^{10}$ En este sentido, la función de estos dos

la creación de empleos), al mismo tiempo que justifican la creación de empleos para los no estigmatizados: dado que los pobres son un problema, necesitan cuerpos de seguridad, trabajadores sociales, incluso investigadores capaces de contener el problema. La utilidad de la estigmatización en sus funciones normativas consiste en la posibilidad de reforzar las normas vigentes; por ejemplo, la estigmatización de las madres solteras fortalece el valor de la familia tradicional; la de los perezosos, la ética del trabajo, etcétera. En su categoría de funciones políticas, la estigmatización permite a los políticos desentenderse de las demandas de los pobres y fortalece ante todo las tendencias conservadoras. Finalmente, a nivel macrosocial, la estigmatización permite un nivel bajo de servicios para este sector, asegurando así la exterminación de la sobrepoblación, en el sentido malthusiano.

${ }^{10}$ Es el caso frecuente de programas de apoyo a mujeres jefas de familia, a las que se presenta como víctimas de irresponsabilidad de los varones, no como sujetos de su propio destino. Las noticias sobre los programas focalizados a mujeres jefas de familia 
elementos es contradictoria y se necesita una reflexión más seria sobre si la ventaja de construir el apoyo social a un programa focalizado es más importante que el riesgo de reproducir y fortalecer estereotipos, que minan la igualdad simbólica de distintos grupos.

\section{CONCLUSIONES}

El debate sobre las ventajas y desventajas de los programas sociales focalizados ocupa un espacio relevante en la reflexión sobre las políticas públicas y su impacto en la construcción de una sociedad justa. Es innegable que en todas las sociedades existe la necesidad de programas orientados a grupos específicos, que son financiados con recursos públicos, y por ende despiertan debates frecuentemente acalorados sobre si los beneficiarios merecen este apoyo. Sin embargo, más allá de estos debates, es necesario profundizar en la reflexión sobre la forma en que el diseño y el proceso de comunicación en torno a estos programas contribuye a reproducir la estigmatización de los grupos vulnerables, y si es así, sobre cómo revertir este fenómeno y aprovechar el encuadramiento para modificar los estereotipos negativos, fortalecer la igualdad simbólica, al mismo tiempo que la material, y de esta manera, asegurar también el acceso no solamente a los bienes materiales, sino también a los simbólicos, que constituyen el fundamento social del respeto a sí mismo, por ende del empoderamiento y la habilitación como ciudadanos de pleno derecho.

\section{FUENTES CONSULTADAS}

Bauman, Z. (2002), En busca de la política, México: Fondo de Cultura Económica (FCE).

aparecen frecuentemente en el contexto del Día de la Madre, recordando la contribución fundamental de la mujer a la construcción de una buena sociedad, pero reforzando también la imagen de agradecimiento hacia políticos (en su mayoría, varones), desde el discurso privado del afecto, y no el discurso público del derecho. 
Blinder, S. B. (2007), "Dissonance Persists. Reproduction of Racial Attitudes among Post-Civil Rights Cohorts of White Americans", en American Politics Research, vol. 35, núm. 3, mayo-junio, Urbana-Champaign, IL: Sage/University of Illinois, pp. 299-335.

Вово, L. (1998), "Race, Interest, and Beliefs About Affirmative Action", en: American Behavioral Scientist, vol. 41, núm. 7, abril, Thousand Oaks, California: Sage Publications, pp. 985-1003.

—, Kluegel, J. R. (1993), "Opposition to Race-Targeting: SelfInterest, Stratification Ideology, or Racial Attitudes?", en American Sociological Review, núm. 58, agosto-septiembre, Washington, DC: American Sociological Association, pp. 443-464.

Comisión Económica para América latina (cepal) (2000), Equidad, desarrollo y ciudadanía, Santiago de Chile: CEPAL.

Dahrendorf, R. (1995), "Preserving Prosperity", en New Statesman and Society, vol. 8, núm. 383, 13-29 de diciembre, Londres: New Statesman, Ltd., pp.36-40.

Esping-Andersen, G. (1990), The Three Worlds of Welfare Capitalism, Cambridge, Reino Unido: Polity.

Filgueira, C. H., Filgueira, F. (2002), "Models of Welfare and Models of Capitalism: The Limits of Transferability", en: Evelyne Huber (ed.), Models of Capitalism. Lessons for Latin America, University Park, Pennsylvania: The Pennsylvania State University Press, pp. 127-157.

Fraser, N. (1997), “¿De la redistribución al reconocimiento? Dilemas en torno a la justicia en una época 'postsocialista"'. Artículo en línea disponible en www.cholonautas.edu.pe. 9 de noviembre de 2009.

Gainous, J. (2008), "Who's Ambivalent and Who's Not? Social Welfare Ambivalence Across Ideology", en American Politics Research, vol.36, núm. 2, marzo-abril, Urbana-Champaign, Illinois: Sage/ University of Illinois, pp. 210-235.

Gans, H. J. (1992), "Positive Functions of the Undeserving Poor: Uses of the Underclass in America", en Politics and Society, vol. 22, núm. 3, septiembre-noviembre, Washington, DC: Sage, pp. 269-283.

Gilens, M. (1999), Why Americans Hate Welfare. Race, Media, and the Politics of Antipoverty Policy, Chicago: The University of Chicago Press. 
Gordon, S. R. (2003), Ciudadanía y derechos. ¿Criterios distributivos?, Santiago de Chile: Cepal, Serie Políticas Sociales, 70, julio.

Gordon, L. (2001), "Who Deserves Help? Who Must provide?", en Annals, 577, septiembre-octubre, Filadelfia: The American Academy of Political and Social Science, pp. 12-25.

Hernández, D., Orozco, M., Vázquez, S. (2005), La focalización como estrategia de política pública, México: Secretaría de Desarrollo Social (Sedesol), Serie Documentos de Investigación, 25, noviembre.

Hetling, A., McDermott, M. L., Mapps, M. (2008), "Symbolism versus Policy Learning. Public Opinion of the 1996 u. s. Welfare Reforms", American Politics Research, vol. 36, núm. 3, mayo-junio, UrbanaChampaign, Illinois: Sage/University of Illinois, pp. 335-357.

Huber, E. (1996), "Options for Social Policy in Latin America: Neoliberal versus Social Democratic Models", en Gøsta Esping-Andersen (ed.), Welfare States in Transition. National Adaptions in Global Economies, Londres: Sage, pp. 141-191.

Kershnar, S. (1999), "Strong Affirmative Action Programs and Disproportionate Burdens", en The Journal of Value Inquiry, vol. 33, núm. 2, junio-agosto, Dordrecht: Springer, pp. 201-209.

Larsen, C. A. (2008), "The Institutional Logic of Welfare Attitudes. How Welfare Regimes Influence Public Support", en Comparative Political Studies, vol. 41, núm. 2, febrero, Londres: Sage, pp. 145-168.

Lowi, T. J. (2000), "Políticas públicas, estudios de caso y teoría política", en Luis F. Aguilar Villanueva (ed.), La hechura de las políticas, México: Miguel Ángel Porrúa, pp. 89-117.

Marshall, T. H., Bottomore, T. (1992), Citizenship and Social Class, Chicago: Pluto Press.

Ochman, M. (2008), "El reto de la cohesión social en la integración latinoamericana: una aproximación teórica", en: Ángel María Casas Gragea y Marta Ochman (coords.) Integración, desarrollo e interregionalismo en las relaciones entre la Unión Europea y América latina, México: Escuela de Graduados en Administración Pública (EGAP)-Instituto Tecnológico y de Estudios Superiores de Monterrey (ITESm)/Miguel Ángel Porrúa, pp. 173-206. 
Rawls, J. (2003), Liberalismo político, 4a reimpr., México: FCE. (1995), Teoría de la justicia, 2a ed., México: FCE.

SeFton, T. (2006), "Distributive and Redistributive Policy", en Michael Moran, Martin Rein y Robert E. Goodin (eds.), The Oxford Handbook of Public Policy, Oxford: Oxford University Press, pp. 607-623.

Fecha de recepción: 8 de noviembre de 2013 Fecha de aceptación: 08 de agosto de 2014 
